\title{
Safety and short-term outcomes of endoscopic submucosal dissection for early gastric cancer in elderly patients
}

Authors

Institutions
Minoru Kato ${ }^{1,2}$, Tomoki Michida ${ }^{3}$, Akira Kusakabe ${ }^{1}$, Ayako Sakai $^{1}$, Chihiro Hibino ${ }^{1}$, Mina Kato ${ }^{1}$, Yuki Tokuda', Tomoyo Kawai ${ }^{1}$, Mina Hamano ${ }^{1}$, Miho Chiba ${ }^{1}$, Kosaku Maeda ${ }^{1}$, Katsumi Yamamoto ${ }^{1}$, Masafumi Naito ${ }^{1}$, Toshifumi Ito ${ }^{1}$

\author{
Department of Gastroenterology, Japan Community Healthcare Organization Osaka Hospital, Osaka, Japan \\ 2 Department of Gastrointestinal Oncology, Osaka Medical Center for Cancer and Cardiovascular Diseases, Osaka, Japan \\ Third department of Internal Medicine, Teikyo University Medical Center, Chiba, Japan
}

submitted

11. September 2015 accepted after revision 1. February 2016

\section{Bibliography}

DOI http://dx.doi.org/

10.1055/s-0042-102650

Published online: 28.4.2016

Endoscopy International Open

(c) Georg Thieme Verlag KG

Stuttgart · New York

E-ISSN 2196-9736

\section{Corresponding author}

\section{Tomoki Michida, MD, PhD}

Third Department of Internal Medicine

Teikyo University Medical

Center

3426-3, Anesaki

Ichihara-shi

Chiba, 299-0111

Japan

Fax: +81-436-62-1269

tmichida@med.teikyo-u.ac.jp
2016; 04: E521-E526

Background and study aims: Endoscopic submucosal dissection (ESD) has become widely accepted as a minimally invasive treatment for early gastric cancer (EGC), and opportunities to use ESD to treat EGC in elderly patients are increasing. The objective of this study was to elucidate the safety and efficacy of ESD in elderly patients.

Patients and methods: Between April 2006 and March 2013, a total of 892 patients with EGC were prospectively recruited to undergo ESD according to definite inclusion criteria. The shortterm outcomes and incidence of complications in 345 of these patients who were 75 years of age or older (elderly group) were compared with the short-term outcomes and incidence of complications in the remaining 547 patients (non-elderly group). Factors associated with the occurrence of pneumonia and delirium were also investigated. Results: The $\mathrm{R} 0$ resection rate did not differ between the two groups (96.2\% in the elderly group

\section{Introduction}

\section{$\nabla$}

Endoscopic submucosal dissection (ESD) has been widely accepted as a promising treatment for early gastric cancer (EGC) with a negligible risk for lymph node metastasis. Because ESD is less invasive than surgical resection, it is increasingly used for elderly patients $[1,2]$. On the other hand, ESD is more frequently associated with complications such as perforation and bleeding, and the procedure time is longer than that for conventional endoscopic mucosal resection [1,3]. In addition, sedation-related complications such as postoperative pneumonia and delirium can occur because patients must be deeply sedated during the long procedure. Elderly patients undergo agerelated decline in both physical and cognitive function, so they may be more susceptible than younger patients to such complications.
Some reports regarding the complications of gastric ESD in elderly patients have been published vs. $96.7 \%$ in the non-elderly group; $P=0.65$ ). The incidence of pneumonia ( $7.5 \%$ vs. $1.8 \% ; P<0.01)$ and incidence of delirium $(10.1 \%$ vs. $1.1 \%$; $P<$ 0.01 ) were significantly higher in the elderly group. The incidence of post-ESD bleeding and incidence of perforation were similar in the two groups. No emergency surgery was required, but one patient in the non-elderly group died of aspiration pneumonia. On multivariate analysis, age 75 years or older, cerebrovascular disease, chronic obstructive pulmonary disease, delirium, and remnant stomach or gastric tube were independent risk factors for pneumonia, and age 75 years or older, diabetes, dementia, and pneumonia were independent risk factors for delirium.

Conclusion: ESD for EGC was feasible for elderly patients in good condition. However, pneumonia and delirium may develop more frequently after ESD in elderly patients with co-morbidities.

[2,4-7]. However, these reports have focused mainly on perforation and bleeding, and not much has been done to clarify the incidence of other complications, such as pneumonia and delirium, after ESD in elderly patients. The aim of the present study, therefore, was to elucidate the incidence of pneumonia and delirium after ESD in elderly patients, and to evaluate the safety and efficacy of ESD in elderly patients recruited into a prospective study.

\section{Patients and methods \\ $\nabla$}

Patients and inclusion criteria for endoscopic submucosal dissection

Between April 2006 and March 2013 at Japan Community Healthcare Organization Osaka Hospital, a total of 892 patients with EGC were prospectively recruited for and underwent ESD according to definite inclusion criteria, which were 
as follows: (i) differentiated-type cancer without definite signs of submucosal invasion, up to $30 \mathrm{~mm}$ in diameter regardless of ulceration or more than $30 \mathrm{~mm}$ in diameter without ulceration; (ii) undifferentiated-type cancer up to $20 \mathrm{~mm}$ in diameter without definite signs of submucosal invasion and ulceration, according to guidelines of the Japanese Gastric Cancer Association [8]. Only patients in good condition whose Eastern Cooperative Oncology Group performance status was grade 0,1 , or 2 were selected for gastric ESD.

The baseline clinical data of the recruited patients and the outcomes of ESD were prospectively collected, and we used the database to analyze retrospectively the safety and efficacy of ESD in elderly patients. The patients were divided into an elderly group (345 patients $\geq 75$ years of age) and a non-elderly group (the remaining 547 patients). Because most previously published reports have defined elderly patients as those 75 years of age or older [2,4-7], we adopted the same definition. The two groups were compared in regard to patient and lesion characteristics, outcomes of ESD (en bloc resection rate, R0 resection rate, curative resection rate, procedure time, and duration of hospitalization), and incidence of complications (pneumonia, delirium, perforation, and post-ESD bleeding). We also evaluated the risk factors for pneumonia and delirium. This study was approved by the ethics committee of Japan Community Healthcare Organization Osaka Hospital.

\section{Endoscopic submucosal dissection procedure}

Patients were usually admitted to the hospital the day before ESD. The ESD procedure was performed with the patient under deep sedation induced by diazepam and meperidine with or without propofol. We administered butylscopolamine for an antispasmodic effect. To prevent aspiration pneumonia, we used an overtube during the procedure and suctioned the oral cavity to remove any saliva or exudate. The electrocardiogram, percutaneous oxygen saturation, and blood pressure were monitored during ESD, which was performed with an insulated-tip (IT) knife (KD-610L; Olympus Medical Systems, Tokyo, Japan) and a highfrequency power supply unit (VIO300D; ERBE Elekromedizin, Tübingen, Germany).

The ESD procedure was conducted as follows: First, marks were made along the outline of the lesion with a needle-knife (KD-1L1; Olympus). Epinephrine diluted in saline solution (1:100000) was injected into the submucosal layer around the lesion. Next, an initial incision was made outside the marked area with a needle-knife, and an IT knife was inserted into the initial incision. After circumferential cutting around the marks, the lesion was completely removed by submucosal dissection. After the lesion had been resected, all visible vessels on the ulcer floor were coagulated with hot biopsy forceps (Radial Jaw 4; Boston Scientific Japan, Tokyo, Japan).

Second- and third-look endoscopy procedures were performed on day 1 and day 7 after ESD for evaluation of the post-ESD ulcer and endoscopic hemostasis if needed. Patients without perforation or bleeding started to drink water 1 day after ESD and to consume soft food 2 days after ESD. A normal diet was allowed on day 7. Patients without any complications were discharged from the hospital on day 8 or day 9 after ESD.

Patients taking antiplatelet or anticoagulant drugs were instructed to discontinue them according to the Japan Gastroenterological Endoscopy Society guidelines [9]. Patients whom the prescribing physician judged to have a high risk for thromboembolism received heparin replacement.

\section{Definitions}

En bloc resection was defined as resection in one piece. $\mathrm{R} 0$ resection of a lesion was defined as resection in one piece with margins free of tumor. Curative resection was defined as a resected specimen meeting the requirements for $\mathrm{R} 0$ resection, without invasion into the lymph duct or venous duct, and meeting one of the following four specifications of the Japanese Gastric Cancer Association [8]: (i) differentiated-type mucosal cancer without ulceration; (ii) differentiated-type mucosal cancer with ulceration and up to $30 \mathrm{~mm}$ in diameter; (iii) differentiated-type minute submucosal cancer (SM1) without ulceration and up to $30 \mathrm{~mm}$ in diameter; (iv) undifferentiated-type mucosal cancer without ulceration and up to $20 \mathrm{~mm}$ in diameter. Procedure time was defined as the interval between the first marking and completion of the submucosal dissection. Post-ESD bleeding was defined as bleeding requiring emergency endoscopy or transfusion, or as a decrease in the hemoglobin level of more than $2 \mathrm{~g} / \mathrm{dL}$ following ESD. Perforation was diagnosed endoscopically or by the presence of free air on an abdominal plain radiograph or computed tomogram after ESD. Pneumonia was diagnosed by the presence of a clinical finding such as high fever (defined as a body temperature above $38.0^{\circ} \mathrm{C}$ ), rales, cough, or a decline in oxygen saturation with the presence of a pneumonia shadow on chest radiography or computed tomogram. Postoperative delirium was diagnosed according to the following criteria, which are derived from the Diagnostic and Statistical Manual of Mental Disorders, Fourth edition, Text Revision (DSM-IV-TR) [10]: (i) a disturbance of consciousness with reduced ability to focus, sustain, or shift attention; (ii) a change in cognition or the development of a perceptual disturbance that is not better accounted for by a preexisting, established, or evolving dementia; (iii) the disturbance develops over a short period of time and tends to fluctuate during the course of the day; (iv) there is evidence from the history, physical examination, or laboratory findings that the disturbance is caused by the direct physiological consequences of a general medical condition.

\section{Statistical analysis}

Results were compared with the chi-squared test and Student's $t$ test. A $P$ value of less than 0.05 was considered to be significant. Multivariate logistic regression analysis was performed to identify risk factors that significantly affected postoperative pneumonia and delirium. Quantitative data were expressed as mean and standard deviation (SD). JMP 10.0 (SAS Institute, Cary, North Carolina, USA) was used for data analysis.

\section{Results}

$\nabla$

\section{Characteristics of patients and lesions}

The characteristics of the patients and lesions in the two groups are shown in Table 1. The male-to-female ratio was significantly higher in the non-elderly group $(69.0 \%$ in the elderly group vs. $80.6 \%$ in the non-elderly group; $P<0.01$ ). The incidence of comorbidities, such as hypertension, diabetes, heart disease, cerebrovascular disease, chronic obstructive pulmonary disease (COPD), and dementia, was significantly higher in the elderly group. The majority of the patients in both groups had not undergone surgery for gastric or esophageal cancer and had an unresected normal stomach. The percentage of patients taking anticoagulants and antiplatelet agents was significantly higher in the elderly group ( $25.2 \%$ vs. $11.9 \%$; $P<0.01$ ). No significant differen- 


\begin{tabular}{|c|c|c|c|}
\hline & Elderly group & Non-elderly group & $P$ value \\
\hline \multicolumn{4}{|l|}{ Patient characteristics } \\
\hline Patients, $\mathrm{n}$ & 345 & 547 & \\
\hline Age, mean $\pm S D, y$ & $80 \pm 4$ & $65 \pm 7$ & \\
\hline Sex, n (\%) & & & $<0.01$ \\
\hline Male & $238(69.0)$ & $441(80.6)$ & \\
\hline Female & $107(31.0)$ & $106(19.3)$ & \\
\hline \multicolumn{4}{|l|}{ Co-morbidities, n (\%) } \\
\hline Hypertension & $165(47.8)$ & $186(34.0)$ & $<0.01$ \\
\hline Diabetes mellitus & $67(19.4)$ & $78(14.3)$ & 0.04 \\
\hline Heart disease & $41(11.9)$ & $25(4.6)$ & $<0.01$ \\
\hline Cerebrovascular disease & $43(12.5)$ & $21(3.8)$ & $<0.01$ \\
\hline Chronic renal failure & $26(7.5)$ & $29(5.3)$ & 0.18 \\
\hline Liver cirrhosis & $8(2.3)$ & $14(2.6)$ & 0.82 \\
\hline COPD & $66(19.1)$ & $60(11.0)$ & $<0.01$ \\
\hline Dementia & $26(7.5)$ & $7(1.3)$ & $<0.01$ \\
\hline Condition of stomach & & & 0.87 \\
\hline Normal stomach & $337(97.7)$ & $536(98.0)$ & \\
\hline Remnant stomach & $6(1.7)$ & $6(1.1)$ & \\
\hline Gastric tube & $2(0.6)$ & $5(0.9)$ & \\
\hline $\begin{array}{l}\text { Use of anticoagulant and/or } \\
\text { antiplatelet drugs, } n(\%)\end{array}$ & $87(25.2)$ & $65(11.9)$ & $<0.01$ \\
\hline \multicolumn{4}{|l|}{ Lesion characteristics } \\
\hline Lesions, $\mathrm{n}$ & 421 & 641 & \\
\hline Location, n (\%) & & & 0.59 \\
\hline Upper & $77(18.3)$ & $102(15.9)$ & \\
\hline Middle & $210(49.9)$ & $332(51.8)$ & \\
\hline Lower & $134(31.8)$ & $207(32.3)$ & \\
\hline Mean tumor size, $\mathrm{mm}$ & $17.5 \pm 14.0$ & $16.6 \pm 12.1$ & 0.14 \\
\hline Histologic type & & & 0.16 \\
\hline Differentiated & $408(96.9)$ & $610(95.2)$ & \\
\hline Undifferentiated & $13(3.1)$ & $31(4.8)$ & \\
\hline Ulceration findings, $\mathrm{n}(\%)$ & & & 0.58 \\
\hline Present & $56(13.3)$ & $93(14.5)$ & \\
\hline Absent & $365(86.7)$ & $548(85.5)$ & \\
\hline Depth, n (\%) & & & 0.19 \\
\hline Intramucosal & $386(91.7)$ & $572(89.2)$ & \\
\hline Deeper than intramucosal & $35(8.3)$ & $69(10.8)$ & \\
\hline
\end{tabular}

Table 1 Characteristics of the patients and lesions in a study of the safety and short-term outcomes of endoscopic submucosal dissection for early gastric cancer in elderly patients.

SD, standard deviation; COPD, chronic obstructive pulmonary disease.

ces were observed between the groups in regard to size, location, histologic type, ulceration findings, and depth of the tumors.

\section{Outcomes of endoscopic submucosal dissection}

The two groups had no significant differences in procedure time, en bloc resection rate $(99.3 \%$ vs. $99.2 \% ; P=0.90)$, R0 resection rate (96.2\% vs. $96.7 \% ; P=0.65)$, and curative resection rate $(91.2 \%$ vs. $88.0 \% ; P=0.10)$. The duration of hospitalization was similar in the two groups ( $\bullet$ Table 2$)$.

\section{Incidence of complications}

The incidence of complications is shown in $\bullet$ Table 3 . The incidence of pneumonia ( $7.5 \%$ vs. $1.8 \% ; P<0.01)$ and incidence of delirium $(10.1 \%$ vs. $1.1 \% ; P<0.01)$ were significantly higher in the elderly group.

One patient in the non-elderly group died of pneumonia. This patient was 74-year-old man who had previously undergone esophagectomy with gastric tube reconstruction for esophageal cancer, and he also had COPD. ESD was performed to remove three lesions at the same time, and the procedure took 250 minutes. During the lengthy procedure, the patient aspirated gastric juice, and pneumonia subsequently developed. Delirium also developed in this patient after ESD, and aspiration occurred several times during the postoperative period. Although he was transferred to the intensive care unit and underwent intubation, he died on day 21 after ESD. The other patients who had pneumonia recovered well with antibiotic treatment. The mean hospital stay was significantly longer for the patients with pneumonia $(14 \pm 3$ days in the pneumonia cases vs. $12 \pm 3$ days in the non-pneumonia cases; $P<0.01$ ).

Of the 41 patients in whom delirium developed, only 3 (7.3\%) required pharmacologic intervention; the others recovered spontaneously in a few days. The development of delirium did not prolong the duration of hospitalization $(12 \pm 4$ days in the delirium cases vs. $12 \pm 3$ days in the non-delirium cases; $P=0.25$ ). The incidence of post-ESD bleeding and incidence of perforation were similar in the two groups. No emergency surgery was necessary for any of the patients.

\section{Risk factors for pneumonia and delirium}

Univariate analysis showed that age 75 years or older, cerebrovascular disease, COPD, dementia, remnant stomach or gastric tube, and delirium were risk factors for pneumonia ( $\bullet$ Table 4$)$. Multivariate analysis demonstrated that age 75 years or older (odds ratio [OR] 2.83, 95\% confidence interval [CI] 1.30-6.54], cerebrovascular disease (OR 3.60, 95\%CI 1.44-8.32), COPD (OR 
Table 2 Outcomes of endoscopic submucosal dissection.

\begin{tabular}{|c|c|c|c|}
\hline & $\begin{array}{l}\text { Elderly } \\
\text { group }\end{array}$ & $\begin{array}{l}\text { Non-elderly } \\
\text { group }\end{array}$ & $P$ value \\
\hline $\begin{array}{l}\text { Procedure time, } \\
\text { mean } \pm S D \text {, min }\end{array}$ & $54 \pm 37$ & $50 \pm 39$ & 0.11 \\
\hline En bloc resection, $\mathrm{n}(\%)$ & $418(99.3)$ & $636(99.2)$ & 0.90 \\
\hline $\mathrm{R} 0$ resection, $\mathrm{n}(\%)$ & $405(96.2)$ & $620(96.7)$ & 0.65 \\
\hline Curative resection, $\mathrm{n}(\%)$ & $384(91.2)$ & $564(88.0)$ & 0.10 \\
\hline Hospital stay, mean $\pm S D, d$ & $12 \pm 3$ & $11 \pm 4$ & 0.09 \\
\hline
\end{tabular}

SD, standard deviation.

Table 3 Incidence of complications related to endoscopic submucosal dissection.

\begin{tabular}{|llcl|}
\hline & $\begin{array}{l}\text { Elderly group, } \\
\mathbf{n}(\%)\end{array}$ & $\begin{array}{l}\text { Non-elderly } \\
\text { group, } \mathbf{n}(\%)\end{array}$ & P value \\
\hline Pneumonia & $26(7.5)$ & $10(1.8)$ & $<0.01$ \\
\hline Delirium & $35(10.1)$ & $6(1.1)$ & $<0.01$ \\
\hline Bleeding & $13(3.8)$ & $27(4.9)$ & 0.41 \\
\hline $\begin{array}{l}\text { Perforation } \\
\text { Requiring } \\
\text { emergency surgery }\end{array}$ & $25(7.2)$ & $34(6.2)$ & 0.55 \\
\hline $\begin{array}{l}\text { Procedure-related } \\
\text { death }\end{array}$ & $0(0)$ & $0(0)$ & \\
\hline
\end{tabular}

1 Died of repeated aspiration pneumonia.

Table 4 Univariate analysis of risk factors for pneumonia.

\begin{tabular}{|c|c|c|c|}
\hline & $\begin{array}{l}\text { Pneumonia } \\
\text { group, n (\%) }\end{array}$ & $\begin{array}{l}\text { Control group, } \\
\text { n (\%) }\end{array}$ & $P$ value \\
\hline Age $\geq 75 y$ & $26(72.2)$ & $319(37.3)$ & $<0.01$ \\
\hline Sex & & & 0.97 \\
\hline Male & $28(77.8)$ & $651(76.0)$ & \\
\hline Female & $8(22.2)$ & $205(24.0)$ & \\
\hline \multicolumn{4}{|l|}{ Co-morbidities } \\
\hline Hypertension & $14(38.9)$ & $337(39.4)$ & 0.95 \\
\hline Diabetes mellitus & $9(25.0)$ & $136(15.9)$ & 0.22 \\
\hline Heart disease & $4(11.1)$ & $62(7.2)$ & 0.59 \\
\hline $\begin{array}{l}\text { Cerebrovascular } \\
\text { disease }\end{array}$ & $9(25.0)$ & $55(6.4)$ & $<0.01$ \\
\hline Chronic renal failure & $4(11.1)$ & $51(6.0)$ & 0.37 \\
\hline Liver cirrhosis & $2(5.6)$ & $20(2.3)$ & 0.51 \\
\hline COPD & $12(33.3)$ & $114(13.3)$ & $<0.01$ \\
\hline Dementia & $4(11.1)$ & $28(3.3)$ & 0.04 \\
\hline $\begin{array}{l}\text { Remnant stomach } \\
\text { or gastric tube }\end{array}$ & $4(11.1)$ & $15(1.8)$ & $<0.01$ \\
\hline Procedure time $\geq 2 \mathrm{~h}$ & $3(8.3)$ & $54(6.3)$ & 0.89 \\
\hline Perforation & $0(0)$ & $59(6.9)$ & 0.20 \\
\hline Bleeding & $2(5.6)$ & $38(4.4)$ & 0.93 \\
\hline Delirium & $9(25.0)$ & $32(3.7)$ & $<0.01$ \\
\hline Total & 36 & 856 & \\
\hline
\end{tabular}

COPD, chronic obstructive pulmonary disease.

2.64, 95\%CI 1.16-5.72), delirium (OR 5.32, 95\%CI 1.64-15.80), and remnant stomach or gastric tube (OR 5.30, 95\%CI $1.25-$ 18.46) were independent risk factors ( $\bullet$ Table 5$)$.

Univariate analysis revealed that age of 75 years or older, diabetes, heart disease, cerebrovascular disease, chronic renal failure, dementia, and pneumonia were risk factors for delirium ( Table6). Multivariate analysis demonstrated that age older than 75 years (OR 5.29, 95\%CI 2.04-15.96), diabetes (OR 2.46,
Table 5 Multivariate logistic regression analysis for pneumonia.

\begin{tabular}{|lll|}
\hline & Odds ratio $(\mathbf{9 5} \% \mathbf{C I})$ & $\boldsymbol{P}$ value \\
\hline Age $\geq 75 y$ & $2.83(1.30-6.54)$ & $<0.01$ \\
\hline Cerebrovascular disease & $3.60(1.44-8.32)$ & $<0.01$ \\
\hline COPD & $2.64(1.16-5.72)$ & 0.02 \\
\hline Dementia & $0.75(0.16-3.12)$ & 0.70 \\
\hline Delirium & $5.32(1.64-15.80)$ & $<0.01$ \\
\hline Remnant stomach or gastric tube & $5.30(1.25-18.46)$ & 0.03 \\
\hline
\end{tabular}

$\mathrm{Cl}$, confidence interval; $\mathrm{COPD}$, chronic obstructive pulmonary disease.

Table 6 Univariate analysis of risk factors for delirium.

\begin{tabular}{|c|c|c|c|}
\hline & $\begin{array}{l}\text { Delirium } \\
\text { group, n (\%) }\end{array}$ & $\begin{array}{l}\text { Control group, } \mathbf{n} \\
(\%)\end{array}$ & $P$ value \\
\hline Age $\geq 75 y$ & $35(85.4)$ & $310(36.4)$ & $<0.01$ \\
\hline Sex & & & 0.39 \\
\hline Male & $34(82.9)$ & $645(75.8)$ & \\
\hline Female & $7(17.1)$ & $206(24.2)$ & \\
\hline \multicolumn{4}{|l|}{ Co-morbidities } \\
\hline Hypertension & $18(43.9)$ & $333(39.1)$ & 0.54 \\
\hline Diabetes mellitus & $15(36.6)$ & $130(15.3)$ & $<0.01$ \\
\hline Heart disease & $7(17.1)$ & $59(6.9)$ & 0.03 \\
\hline $\begin{array}{l}\text { Cerebrovascular } \\
\text { disease }\end{array}$ & $9(22.0)$ & $55(6.5)$ & $<0.01$ \\
\hline Chronic renal failure & $8(19.5)$ & $47(5.2)$ & $<0.01$ \\
\hline Liver cirrhosis & $1(2.4)$ & $21(2.5)$ & 0.61 \\
\hline COPD & $8(19.5)$ & $118(13.9)$ & 0.43 \\
\hline Dementia & $21(51.2)$ & $11(1.3)$ & $<0.01$ \\
\hline $\begin{array}{l}\text { Remnant stomach } \\
\text { or gastric tube }\end{array}$ & $2(4.9)$ & $17(2.0)$ & 0.48 \\
\hline Procedure time $\geq 2 \mathrm{~h}$ & $5(12.2)$ & $52(6.1)$ & 0.22 \\
\hline Perforation & $4(9.8)$ & $55(6.5)$ & 0.61 \\
\hline Bleeding & $3(7.3)$ & $37(4.3)$ & 0.61 \\
\hline Pneumonia & $9(22.0)$ & $27(3.2)$ & $<0.01$ \\
\hline Total & 41 & 851 & \\
\hline
\end{tabular}

COPD, chronic obstructive pulmonary disease.

Table 7 Multivariate logistic regression analysis for delirium.

\begin{tabular}{|lll|}
\hline & Odds ratio $(95 \% \mathbf{C l})$ & P value \\
\hline Age $\geq 75$ y & $5.29(2.04-15.96)$ & $<0.01$ \\
\hline Diabetes mellitus & $2.46(1.03-5.74)$ & 0.04 \\
\hline Chronic renal failure & $1.63(0.50-4.84)$ & 0.40 \\
\hline Cerebrovascular disease & $2.74(0.92-7.52)$ & 0.07 \\
\hline Heart disease & $1.21(0.38-3.44)$ & 0.72 \\
\hline Dementia & $52.29(20.61-143.29)$ & $<0.01$ \\
\hline Pneumonia & $5.28(1.69-15.32)$ & $<0.01$ \\
\hline
\end{tabular}

$\mathrm{Cl}$, confidence interval.

95\%CI 1.03-5.74), dementia (OR 52.29, 95\%CI 20.61-143.29), and pneumonia (OR 5.28, 95\%CI 1.69-15.32) were independent risk factors ( $\bullet$ Table 7$)$.

\section{Discussion}

In this study, the curative resection rates and procedure times for ESD were similar in the elderly and non-elderly patients. However, pneumonia and delirium were more often encountered after gastric ESD in the elderly patients. Furthermore, cerebro- 
vascular disease and COPD independently increased the risk for pneumonia, and delirium occurred significantly more often in patients with a history of diabetes or dementia. Thus, careful attention should be paid to pneumonia and delirium when elderly patients with these co-morbidities undergo gastric ESD.

In this study, the rate of pneumonia in the entire group was $4.0 \%$ (36/892). Akasaka et al. reported a large retrospective study of postoperative pneumonia after ESD in which the incidence $(1.6 \%)$ was lower than ours [11]. The reason for this difference may be that these authors used only chest radiography to diagnose pneumonia, whereas we performed computed tomography whenever the clinical findings strongly suggested pneumonia. Watari et al. reported a rate of postoperative pneumonia after ESD of up to $6.6 \%$ when all patients underwent chest computed tomography the day after ESD [12]. In their study, $66.7 \%$ of the patients with pneumonia detected by computed tomography had no abnormal findings on chest radiography. Therefore, to detect subtle cases of postoperative pneumonia, we recommend that patients undergo chest computed tomography if they have clinical findings such as prolonged fever.

COPD has been reported to be an important patient-related risk factor for pulmonary complications after surgery [13]. Our study showed that it is similarly a risk factor for pulmonary complications after gastric ESD. We found that cerebrovascular disease was also a patient-related risk factor for the development of pneumonia after ESD. One possible reason for this result may be that the swallowing ability of some patients with cerebrovascular disease was impaired, which consequently increased the risk for aspiration. We also found that remnant stomach after gastrectomy or gastric tube after esophagectomy increased the risk for pneumonia. The reason for this result may be that the contents of the small and reconstructed stomach are prone to flow back to the mouth, inducing aspiration. To prevent aspiration, the oral cavity should be sucked frequently to remove any saliva or exudate, and caution should be exercised to avoid sedation that is too deep during the ESD procedure. Care is also needed during the postoperative period.

Delirium is a common, life-threatening clinical syndrome among elderly patients. There are, however, few reports regarding delirium after ESD. In this study, which is the first to assess the incidence of delirium as a complication of ESD, delirium occurred in $10.1 \%$ of the elderly patients. Fortunately, almost all of the patients with delirium recovered after a few days without treatment.

Dementia is the leading risk factor for delirium, and two-thirds of cases of delirium occur in patients with dementia [14]. Similarly, in our results, dementia appeared to be the most significant independent risk factor associated with the development of delirium. Delirium is often multifactorial in origin. In studies of elderly patients, drugs have been reported as the cause of delirium in $11 \%$ to $30 \%$ of cases [14]. Drugs such as benzodiazepines, anticholinergics, and opioids are especially important as causes of delirium [15]. Even in very low doses, butylscopolamine, which we used as an antispasmodic agent, is commonly associated with cognitive changes [16]. Recently, Fujishiro at al. proved the antispasmodic effectiveness and safety of l-menthol in patients undergoing gastric ESD [17]. 1-Menthol is nontoxic substance that is immediately absorbed after being sprayed on the gastric wall. To prevent postoperative delirium in elderly patients, it may be possible to use l-menthol instead of butylscopolamine as an antispasmodic agent. Diazepam and meperidine, which we used to sedate patients in this study, are also major drugs associated with delirium [15]. Recently, dexmedetomidine was approved for use as a sedative drug during endoscopic therapy in Japan. Many studies have shown that the use of dexmedetomidine is associated with a decreased incidence of delirium in the intensive care unit [18]. Therefore, dexmedetomidine may also be a possible choice for preventing delirium after ESD. Further studies are required to demonstrate whether use of the above-mentioned drugs can reduce the incidence of delirium after ESD.

In this study, there were no significant differences in the rates of post-ESD bleeding and perforation between the elderly and nonelderly patients. These results coincide with those of some previous studies $[2,4,5,7]$. Bleeding and perforation seem to be influenced more often by lesion-related factors, such as tumor size and location, than by patient factors $[3,19,20]$.

The $\mathrm{R} 0$ resection rate and curative resection rate in the two groups were similar and satisfactory. The duration of hospitalization was also similar in the two groups. This implies that ESD is a feasible treatment not only for younger patients but also for elderly patients. However, further investigation is required to clarify whether curative ESD helps to increase life expectancy in elderly patients. We have shown that the rates of preexisting comorbidities were significantly higher in the elderly. If these comorbidities are uncontrollable and deemed to be a major prognostic factor, a watch-and-wait strategy may be an option for elderly patients because the overall cumulative 5-year risk for progression of EGC to an advanced stage is reported to be 63\% [21]. Although this was a retrospective, single-center study, all of the data were derived from our prospectively collected database, so there was only a slight chance for selection bias.

In conclusion, our study revealed that ESD for EGC is feasible in elderly patients who are in good condition. However, patients who are in poor condition because of co-morbidities are at increased risk for the postoperative development of pneumonia and delirium. Further studies are required to establish how to minimize such complications.

\section{Competing interests: None}

\section{References}

1 Oka S, Tanaka S, Kaneko I et al. Advantage of endoscopic submucosal dissection compared with EMR for early gastric cancer. Gastrointest Endosc 2006; 64: 877-883

2 Murata A, Muramatsu K, Ichiyama Y et al. Endoscopic submucosal dissection for gastric cancer in elderly Japanese patients: an observational study of financial costs of treatment based on a national administrative database. J Dig Dis 2014; 15: $62-70$

3 Oda I, Gotoda T, Hamanaka H et al. Endoscopic submucosal dissection for early gastric cancer: technical feasibility, operation time and complications from a large consecutive series. Dig Endosc 2005; 17: 54- 58

4 Kakushima N, Fujishiro M, Kodashima $S$ et al. Technical feasibility of endoscopic submucosal dissection for gastric neoplasms in elderly Japanese population. J Gastroenterol Hepatol 2007; 22: 311 - 314

5 Onozato Y, Kakizaki S, Ishihara $\mathrm{H}$ et al. Feasibility of endoscopic submucosal dissection for elderly patients with early gastric cancers and adenomas. Dig Endosc 2008; 20: 12 -16

6 Toyokawa T, Fujita I, Morikawa T et al. Clinical outcomes of ESD for early gastric neoplasms in elderly patients. Eur J Clin Invest 2011; 41: $474-478$

7 Isomoto H, Ohnita K, Yamaguchi $N$ et al. Clinical outcomes of endoscopic submucosal dissection in elderly patients with early gastric cancer. Eur J Gastroenterol Hepatol 2010; 22: 311 - 317

8 Japanese gastric cancer treatment guidelines 2010 (ver.3). Gastric Cancer 2011; 14: $113-123$ 
9 Ogoshi K, Kaneko E, Tada $M$ et al. The management of anticoagulation and antiplatelet therapy for endoscopic procedures [in Japanese]. Gastroenterol Endosc 2005; 47: 2691 - 2695

10 American Psychiatric Association. Diagnostic and statistical manual of mental disorders, fourth edition, text revision. Washington, DC: American Psychiatric Association; 2000

11 Akasaka T, Nishida T, Tsutsui $S$ et al. Short-term outcomes of endoscopic submucosal dissection (ESD) for early gastric neoplasm: multicenter survey by Osaka University ESD Study Group. Dig Endosc 2011; 23: $73-77$

12 Watari J, Tomita T, Toyoshima F et al. The incidence of "silent" free air and aspiration pneumonia detected by $\mathrm{CT}$ after gastric endoscopic submucosal dissection. Gastrointest Endosc 2012; 76: 1116-1123

13 Kroenke K, Lawrence VA, Theroux JF et al. Postoperative complication after thoracic and major abdominal surgery in patients with and without obstructive lung disease. Chest 1993; 104: 1445-1451

14 Inoue SK. Delirium in older persons. N Engl J Med 2006; 354: 1157 1165

15 Moore AR, O'Keeffe ST. Drug-induced cognitive impairment in the elderly. Drugs Aging 1999; 15: $15-28$
16 Molchan SE, Martinez RA, Hill JL et al. Increased cognitive sensitivity to scopolamine with age and a perspective on the scopolamine model. Brain Res 1992; 17: 215-226

17 Fujishiro M, Kaminishi M, Hiki $N$ et al. Efficacy of spraying l-menthol solution during endoscopic treatment of early gastric cancer: a phase III, multicenter, randomized, double blind, placebo-controlled study. J Gastroenterol 2014; 49: 446-454

18 Mo Y, Zimmermann AE. Role of dexmedetomidine for the prevention and treatment of delirium in intensive care unit patients. Ann Pharmacother 2013; 47: 869-876

19 Ohta $T$, Ishihara $R$, Uedo $N$ et al. Factors predicting perforation during endoscopic submucosal dissection for gastric cancer. Gastrointest Endosc 2012; 75: $1159-1165$

20 Okada K, Yamamoto Y, Kasuga A et al. Risk factors for delayed bleeding after endoscopic submucosal dissection for gastric neoplasm. Surg Endosc 2011; 25: 98-107

21 Tsukuma $\mathrm{H}$, Oshima A, Narahara $\mathrm{H}$ et al. Natural history of early gastric cancer: a non-concurrent, long term follow up study. Gut 2000; 47: $618-621$ 